\title{
СОЗДАВАЯ ЦЕННОСТЬ И АУТЕНТИЧНОСТЬ: ГОРОДСКИЕ КОНФЛИКТЫ ВОКРУГ ИСТОРИЧЕСКИХ ЗДАНИЙ
}

Статья раскрывает процессы производства исторической ценности зданий и роль этих процессов в динамике градозащитных конфликтов. Авторы рассматривают три случая, произошедшие в крупных городах России за последние десять лет: конфликты по поводу сноса Блокадной подстанции в Санкт-Петербурге, Арских казарм в Казани и исторической застройки на ул. Ильинской в Нижнем Новгороде. Историческая ценность и аутентичность в этих случаях не существует как данность: в ходе градозащитных конфликтов она заявляется, легитимируется, оспаривается или пересматривается в действиях и риториках различных акторов. Для анализа динамики формирования исторической ценности и аутентичности зданий авторы обращаются к двум понятиям: политика производства аутентичности (politics of authentication) и эстетика убеждения (aesthetics of persuasion). Используя стратегическую интеракционную перспективу - концепцию игроков и арен,- авторы показывают, какую работу выполняет историческая ценность и как она упорядочивает арены конфликта и действия игроков на них. Историческая ценность зданий в исследованных случаях включает в себя, с одной стороны, детальную работу по созданию контекстов, категорий и семантических рядов, в которых здания обретали значение, с другой стороны- получение формального статуса «ценного исторического объекта». (Hе) созданная на тех или иных аренах историческая ценность определяла дальнейший ход конфликта, открывала новые арены, вовлекала новых игроков или отстраняла ранее вовлеченных. Исследование показывает,

Любовь Алексеевна Чернышева- н.с., Социологический институт РАН- филиал Федерального научно-исследовательского социологического центра РАН, Санкт-Петербург, Россия. Электронная почта: 1.a.chernysheva@gmail.com

Анисья Михайловна Хохлова- к. социол.н., доцент, кафедра социологии культуры и коммуникации, Санкт-Петербургский государственный университет, Санкт-Петербург, Россия. Электронная почта: a.khokhlova@spbu.ru 
что объект не просто становится ценностью и закрепляет за собой этот статус в результате работы, проведенной экспертами, лоббистами, политиками, активистами, местными жителями и др. акторами. В исследуемых случаях ценность являлась процедурой, которая актуализируется в момент покушения на здание или его обесценивания, а также включает набор (не)дозволенных способов обращаться со зданием и стратегий достижения того, чтобы дозволенные способы оставались практикой, а недозволенные- не возникали.

Ключевые слова: историческое наследие, аутентичность, городские конфликты, градозащитные движения, стратегическая интеракционная перспектива

DOI: 10.17323/727-0634-2021-19-2-223-238

\section{Как возникает «историческая ценность»}

На фоне неолиберальной урбанизации и развития предпринимательских форм управления городом (Jacobsson, Korolczuk 2020; Mayer 2016) в российских городах в последние десятилетия возникают девелоперские проекты, предполагающие снос существующей городской застройки. Но, как предупреждает известная казанская градозащитница: «Есть такая татарская поговорка: "Старое только тронешь, сам удивишься, что maм nопрет"» (И3)1. «Тронув старое», девелоперы запускают процессы городской мобилизации, в которых оно переопределяется как «ценное», а его снос превращается в покушение на общественное благо. В статье мы прослеживаем, как в ходе подобных конфликтов возникает и работает понятие исторической ценности.

В российской литературе о конфликтах вокруг сноса исторических зданий акцент часто делается на динамике мобилизации и характеристиках городских градозащитных движений, в том числе стратегиях вовлечения горожан в градозащиту (Гладарев 2011), репертуарах действий и самопрезентации градозащитных движений (Платонов, Юдина 2019), их динамике (Тыканова 2019) и политизации (Tykanova, Khokhlova 2020; Зверев 2017). Историческая ценность и аутентичность объектов, вокруг которых разворачивается борьба, предстают здесь фоновыми характеристиками, которые озвучиваются лишь в контексте анализа аргументации градозащитников. Мы же хотим сфокусироваться на содержательной стороне процессов перевоплощения «никому не нужного» здания в «ценный» городской объект, требующий сохранения.

В модернистском подходе объект должен обладать «аутентичностью», чтобы стать исторической ценностью (van de Port, Meyer 2018). Аутентичность, а вместе с ней и историческая ценность рассматриваются как неотъемлемые

\footnotetext{
${ }^{1}$ См. электронное приложение: https://jsps.hse.ru/article/view/12697/12943
} 
свойства объектов: они наблюдаемы, их можно измерить и оценить, причем оценки формулируются языком «объективности» и «беспристрастности» (Bell 2011; Jones 2010). Организации, занимающиеся защитой исторического наследия (например, ЮНЕСКО), опираются на этот подход. Альтернативный конструктивистский подход исходит из того, что объекты не обладают аутентичностью имманентно (van de Port, Meyer 2018): историки, управленцы, критики и др. акторы участвуют в переговорах о ценности объектов и пространств (Jones 2010), а сами объекты получают признание как историческое наследие (или, наоборот, лишаются его) в результате реализации политических интересов и служат инструментом государственной политики (Craith 2007).

Однако конструктивистский подход подвергается критике за то, что оставляет за скобками материальность объектов. Опираясь на чувствительные к материальности методологии (Jones, Yarrow 2013; Foster, Jones 2019), исследователи демонстрируют, как ценность/аутентичность не просто «обнаруживается», но создается в сетях отношений между людьми, объектами, материалами и пространствами в ходе переговоров об этой аутентичности (van de Port, Meyer 2018). Здания не являются неизменными объектами, а становятся наследием, проходя через процессы исследований, консультаций, публичных дебатов, лоббирования, фандрайзинга, бюрократических процедур, политических решений (Jacobs, Merriman 2011).

Маттийс ван де Порт и Биргит Мейер (van de Port, Meyer 2018) предлагают два понятия для анализа динамики формирования исторического наследия: политики производства аутентичности (politics of authentication) и эстетика убеждения (aesthetics of persuasion). Первое позволяет исследовать процессы, в которых объекты получают статус исторического наследия в существующих конфигурациях власти, когда конкурирующие акторы определяют свидетельства ценности объектов. Второе помогает проследить, как наследие символически присваивается и воплощается в жизненном опыте экспертов, активистов и горожан. Эстетика в данном случае означает не то, что оценка объекта как аутентичного/ценного определяется его «красотой», а то, что она основана на трансляции знания, неразрывно связанного с чувственным восприятием (Jethro 2015). Особую роль в этом процессе играет опыт физического соприкосновения людей с материальностью мест и зданий (Jones 2010), который позволяет «соблазнить, увлечь, убедить и мобилизовать» людей, «чтобы они увидели в [культурных] формах свое наследие» (van de Port, Meyer 2018: 20). Создание аутентичности опирается на практики убеждения (Bell 2011): акторы не просто определяют маркеры «ценного», но и адресуют их различным публикам, представляя наследие не только как нечто «выставленное на всеобщее обозрение, но как нечто близко соотносимое с повседневностью и жизненным опытом других» (van de Port, Meyer 2018:23).

Помимо практик экспертизы, консервации, реставрации (Jones, Yarrow 2013), аутентичность и ценность зданий создаются в рамках бюрократических 
процедур и повседневных практик горожан (Bell 2011), а также усилий НКО и социальных движений (van de Port, Meyer 2018). Чтобы учесть многообразие акторов, участвующих в производстве исторической ценности в ситуации конфликта, мы обращаемся к интеракционно-стратегической перспективе (Jasper, Duyvendak 2015) и используем в качестве аналитических инструментов понятия «арен» и «игроков». Игроками являются индивиды и группы, вступающие в процессы согласования своих конкурирующих интересов. Арены- динамические платформы, где в соответствии с определенными правилами разворачивается взаимодействие игроков. Игроки могут выбирать существующие арены или создавать новые, причем результаты взаимодействия на одних аренах могут становиться триггером возникновения или изменения других арен.

В своем исследовании мы опираемся на конструктивистский подход, однако также принимаем во внимание материальные и сенсорные составляющие процессов, связанных с исторической ценностью. Это позволяет нам проследить, как развиваются конфликты, с чего начинается производство историчности и с какими прагматическими трудностями сталкиваются агенты этого производства. В статье мы показываем, какую роль играют политики производства аутентичности и эстетика убеждения в динамике градозащитных конфликтов.

Защита историко-архитектурного наследия является одним из самых распространенных мотивов градостроительных конфликтов (Семенов 2019). Мы сфокусируемся на тех случаях, произошедших за последние десять лет в российских городах-миллионниках, где особенно остро проблематизировалась историческая/архитектурная ценность зданий: это конфликты по поводу сноса Блокадной подстанции в Санкт-Петербурге, Арских казарм в Казани и исторической застройки на Ильинской улице в Нижнем Новгороде. В исследуемых случаях историческая ценность зданий производилась во взаимодействии множества игроков и становилась самостоятельным политическим феноменом (Winner 1980), (пере)определяя процессы согласования интересов в рамках градозащитных конфликтов. Реконструируя динамику каждого конфликта, мы показываем многообразие игроков, с их разновекторными интересами и представлениями о(б) (отсутствии) ценности оспариваемых зданий, и прослеживаем, какие (не)формальные арены они использовали, чтобы заявить о своих правах на эти здания, убеждая себя и других в их ценности или, напротив, публично обесценивая их.

В основу статьи легли собранные в 2019 г. 27 полуформализованных интервью с участниками конфликтов: местными жителями, активистами, градозащитниками, членами общественных организаций, экспертами, чиновниками. Дополнительными материалами для анализа послужили документация экспертиз по вопросу признания зданий объектами культурного наследия (ОКН) и более 70 статей в городских и региональных СМИ, посвященных событиям исследуемых конфликтов. 
«Неочевидные» памятники:

«изобретение» ценности на неформальных аренах

Весной 2009 г. в Санкт-Петербурге стало известно о планах реконструкции здания тяговой подстанции № 11, построенной на наб. реки Фонтанки в 1932 г. Здание, находящееся в собственности СПбГУП «Горэлектротранс», собирались приспособить под гостиницу на средства ООО «Ройял гарденс отель». В архитектурном конкурсе победил проект, предполагавший не реконструкцию, а полный снос подстанции, и градсовет утвердил его в 2011 г. В течение следующих лет «Горэлектротранс» выводил подстанцию из рабочего состояния, а в это время в городе началась кампания по защите здания, инициированная градозащитниками.

Для самих градозащитников подстанция не была «очевидным памятником» (И1). Построенное из силикатного кирпича здание невыразительной формы, не соответствующее контексту места («исторической» застройке набережной),- так они вспоминают свои впечатления от подстанции в интервью. И хотя многие архитекторы называли ее «архитектурнымм недоразумением» (И1), предлагаемая альтернатива- современное здание- казалась градозащитникам еще более неуместной. Поэтому сохранение подстанции представлялось лучшим решением (И2) - тем более, что она «скрывала в себе» ценность иного рода-коммеморативную: в 1942 г. подстанция дала ток для первого трамвая, запущенного в блокадном Ленинграде. Этот факт вписывал подстанцию в контекст городской памяти. Здание по мере погружения градозащитников в его историю превращалось в нечто ценное.

Активисты были вынуждены прикладывать усилия, чтобы сделать обнаруженные исторические контексты видимыми для других (потенциальных) игроков. Так, когда они соединили здание, нависшую над ним угрозу сноса и военную историю города в один семантический ряд, к конфликту подключились члены блокадных организаций. Они утвердили несомненную ценность здания как памятного места и активировали новые арены борьбы за его сохранение, отправляя письма чиновникам и организуя мероприятия у стен подстанции. Все эти арены поощряли новые интеракции игроков, (пере)определяя правила взаимодействия и позиции игроков, а также были способны наделять их ресурсами. С помощью экскурсий, круглых столов, публикаций в традиционных и цифровых медиа, а также пикетов и др. форм уличной политики градозащитники буквально «заставили» (И2) горожан понять ценность типового здания, показав, что его роль в истории уникальна, а особая форма памяти, к которой оно апеллирует, противопоставляет официозу блокадной темы и каноническому образу героизма ленинградцев повседневную память города (И1; И2).

Аналогичные процессы выведения «незаметных» зданий в зону видимости произошли и в случае защиты Арских казарм в Казани. Казармы построены на территории Октябрьского городка в 1903-1911 гг. для артиллерийских 
бригад. В советское время там размещалось Казанское артиллерийское училище, закрытое в 2011 г. Дома на территории городка находились в удручающем состоянии, хотя по-прежнему были заселены. В начале 2010-х гг. Министерство обороны РФ уступило землю компании «Унистрой» для строительства нового жилья с обязательством переселения жителей из аварийных корпусов в новые дома. В 2015 г. утвержденный проект начали реализовывать.

Так начался двухэтапный городской конфликт: сначала вокруг сноса двух общественных зданий детского сада и военторга (2015-2017), а затем- жилых корпусов городка (2019). Градозащитники указывали на связь архитектурного комплекса с традициями российского офицерства (И4) и градостроительную ценность построек (И5), которые «прида[вали] неповторимый облик этому микрорайону» (И6). Как и в случае с подстанцией, градозащитники апеллировали к более широкому контексту недавних городских трансформаций. Если в Петербурге к защите старых зданий подталкивает страх появления новых «плохих» зданий, то в Казани старые здания мыслятся как скудный, а оттого еще более ценный «остаток» былого исторического наследия, практически полностью уничтоженного в 1990-2000-х гг. в ходе бесконтрольных сносов в историческом центре. Снос Арских казарм воспринимался как продолжение «уничтожения Казани», причем даже замглавы аппарата президента Муратов в частной беседе с журналистом признал, что «это же катастрофа, что случилось: опять уничтожают Казань» (И4).

Градозащитники начали с производства ценности зданий городка друг для друга: например, соприкосновение со зданиями во время экскурсий, организованных другими активистами, позволяло многим «понять» ценность территории и включиться в кампанию по ее защите (И7). Но самой сложной задачей было показать, что снос Арских казарм-это не локальное, а общегородское значимое событие, которое касается каждого: «У человека возникает вопрос: "А как это будет относиться ко мне лично?" < .. > "А я в Азино живу, мне пофигу". И в связи с этим привлечение сторонников стало, наверное, главной проблемой» (И7). Чтобы вызвать чувство сопричастности у горожан, активисты вели телеграм-канал, стояли в одиночных пикетах на улицах города и собирали подписи против сноса. Но ресурсов для эффективной медийной огласки события не хватало: многие арены, которые были задействованы в конфликте вокруг Блокадной подстанции (лекции, круглые столы, акции памяти), здесь не были активированы.

Проблема производства исторической ценности казарм для горожан отчасти связана с тем, что их материальность не была «уникальной»: с архитектурной точки зрения это был типовой проект. Но активисты, опираясь на документы ЮНЕСКО, убеждали других игроков, что «критерием отнесения к памятникам является не только их уникальность <..> [Если] даже они типовые военные городки, и такие были по всей России, в этом их иченность тоже есть» (ИЗ). Чтобы типовые здания получили 
ценность в глазах горожан, казанским активистам потребовалось, во-первых, определить, к какому типу объектов они относятся, а во-вторых- поместить казармы в международный контекст. Так, журналист-активист (И4) придумал для характеристики казарм архитектурный стиль «русская военная готика», не зафиксированный ни в одном профильном издании по истории архитектуры, однако это понятие широко разошлось в местных СМИ. Активисты также нашли архитектурный аналог казарм в Финляндии и создали серию публикаций, которые продемонстрировали, как с подобными зданиями бережно обращаются в европейских странах. Этот прием привлек внимание горожан (И4).

Существенное отличие производства ценности Арских казарм от предыдущего случая заключается в том, что в этом конфликте затронуты интересы местных жителей, многие из которых не поддержали градозащитников. Когда последние предлагали придать охранный статус жилым корпусам, они не имели в виду, что люди должны продолжать жить в аварийных домах, но лишь указывали, что плохое состояние объекта не является критерием историко-культурной ценности (ИЗ). Застройщик же воспользовался двусмысленностью ситуации и, по словам активистов, пустил слух о том, что в случае постановки зданий на охрану расселение домов будет остановлено, и переселенцы не получат новые комфортные квартиры. Это сделало невозможной коалицию между градозащитниками и местными жителями. Последние в стремлении добиться обещанного улучшения жилищных условий задействовали новые арены конфликта, написав обращения региональным властям, и определили исход переговоров на формальной арене общественных слушаний, обесценив существующие постройки (И6; И5).

Еще один характерный процесс создания и переопределения исторической ценности мы обнаружили в Нижнем Новгороде. В 2011 г. квартал исторической застройки в границах улиц Ильинской, Горького и Новой перешел с торгов застройщику ООО «Регионинвест 52», аффилированному с тогдашним главой города О. В. Сорокиным. Реализуя свои коммерческие интересы, связанные с созданием престижного микрорайона, в 2013-2015 гг. компания осуществила серию скандальных сносов каменных купеческих особняков и деревянных зданий.

На всем протяжении конфликта градозащитники выступали против уничтожения старых зданий. Для многих активистов историческая и архитектурная ценность находившихся под угрозой домов представлялась бесспорной в силу исторического образования и/или профессионального опыта. Другие, первоначально равнодушные к сосредоточенному в квартале историческому наследию, присоединялись к защите из солидарности с социально и политически активными товарищами. Но чем значительнее и рискованнее становились их «инвестиции» в борьбу (круглосуточные дежурства на оспариваемых территориях, заколачивание окон зданий, чтобы спасти их от поджогов, и даже драки с представителями застрой- 
щика), тем сильнее они ощущали свою сопричастность к судьбе квартала и в конечном итоге оплакивали уничтоженные дома как «родные».

Впрочем, градозащитники были одиноки в своем восприятии зданий на Ильинке как ценных. Городские и региональные власти открыто называли их «развалюхами» и «гнилушками», а подконтрольные им СМИ транслировали этот образ широкой аудитории (И11). Как и в истории Арских казарм, важным игроком конфликта стали жильцы приговоренных к сносу зданий. Большинство из них в стремлении улучшить жилищные условия выступили на стороне застройщика, девальвируя ценность своих домов. Но даже те немногие, кто поддерживал градозащитников, отстаивали свои экономические интересы, а не наследие и идентичность: «У нас не было самой цуели, чтобы он [дом] остался. Мы просто требовали для себя хороших условий» (И12). Горожане также не видели ценности в привычном им архитектурном ландшафте: «Ну, дом-и дом, развалиньл-и развалиньл» (И9).

В стремлении убедить других игроков в ценности квартала градозащитники пытались поместить конфликт в общегородской и даже общероссийский контекст, подчеркивая исчезающую аутентичность исторического центра и особенно- редко где сохранившейся деревянной застройки (И9). Они ввели в публичную дискуссию ярлыки, не стигматизирующие старые дома, а, напротив, артикулирующие их уникальность и ценность-«образцы деревянного модерна и эклектики», «примеры ретроградного провинциального классицизма». Несмотря на широкий репертуар используемых арен и действий, активисты не смогли мобилизовать горожан и оказались беспомощны перед мощным альянсом власти и бизнеса. Тем не менее они сумели извлечь уроки из своих неудач и в последующих конфликтах инициировали новые арены, призванные сформировать у горожан интеллектуальный и чувственный опыт причастности к исторической застройке: запустили серию экскурсий по историческим кварталам в стремлении зафиксировать «уходящую натуру» и переняли самарский опыт организации фестиваля восстановления исторической среды «Том Сойер Фест», в рамках которого волонтеры могут поучаствовать в реставрации аварийных домов. Работая своими руками, физически соприкасаясь с материальностью исторического центра, горожане символически приватизируют отремонтированные здания и готовы при необходимости встать на их защиту.

\section{«Война экспертиз»: борьба за статус исторической ценности на формальных аренах}

В то время как одни арены городского конфликта нацелены на вовлечение сторонников и создание коалиций, другие предполагают открытые столкновения интересов по поводу развития территорий. Одна из таких арен- официальные заседания органов власти, где ценность превращается в документы и статусы, возникающие в рамках (не всегда) регламентиро- 
ванных процедур. Ключевой формальной ареной взаимодействия игроков в Петербурге стали заседания Совета по сохранению культурного наследия при правительстве города- совещательного органа при Комитете по государственному контролю, использованию и охране памятников истории и культуры (КГИОП), состоящего из архитекторов, историков, деятелей культуры и градозащитников. На протяжении конфликта застройщик и его противники предоставляли в Совет ряд конфликтующих историко-культурных экспертиз и оспаривали экспертизы оппонентов. По мере того, как подстанция из типового здания на Фонтанке превращалась в полноценный городской ориентир с артикулированной историей, Совет менял позицию от согласования сноса до признания необходимости включения здания в перечень объектов культурного наследия (ОКН) и обратно (И2).

Параллельно градозащитники инициировали разбирательства на еще одной формальной арене: они направили в районный суд иск с требованием аннулировать выданное застройщику в 2012 г. разрешение на снос подстанции. В 2014 г. суд признал градплан земельного участка, разрешающий застройку, незаконным. ГУП «Горэлектротранс», которое все еще оставалось собственником подстанции, попыталось оспорить данное решение в городском суде, однако отозвало апелляцию весной 2015 г. Таким образом, строительство на месте подстанции теперь юридически невозможно.

Промежуточная победа активистов не означала официального признания подстанции ценным зданием, поэтому защитники продолжали оказывать символическое давление на других игроков, используя инструменты просвещения и уличной политики, а также привлекали деятелей культуры и депутатов ЗакСа для многократных обращений к президенту, министру культуры, губернатору с просьбой присвоить подстанции статус памятника. Наконец, в феврале 2016 г. на встрече с градозащитниками вице-губернатор И.Н. Албин выразил официальную позицию Смольного, подчеркнув значимость подстанции как ОКН. В апреле 2016 г. КГИОП официально включил подстанцию в реестр региональных памятников.

В то время как в петербургском кейсе логика коммерческого развития со временем уступила логике памятования, в казанском кейсе логика прогрессивного и прибыльного городского развития, где «идеальная картинка исторического города - это когда наследие является <...> не потенциалом, а реальным ресурсом, приносящчим доход» (И5), оставалась доминирующей на протяжении всего конфликта. Арские казармы представлялись и застройщику, и региональным властям бесперспективным объектом: "[Пресс-секретарь президента PT] сказал: "[Территория] никому не нужна, ни один турист туда не поедет ее смотреть, поэтому не нужно разжигать на пустом месте"» (И4). Отрицая ценность всех построек, представители застройщика открыто именовали здания детсада и военторга, особо ценные с точки зрения градозащитников, «сараями» (И3) и планировали построить на их месте торговый центр. 
Защитники казарм попытались оспорить заявления других игроков, запустив процесс производства формальной исторической ценности казарм. В 2015 г. казанское отделение общества охраны памятников истории и культуры, осуществив инвентаризацию объектов на территории городка, направило в Минкульт РТ письмо с предложением внести некоторые из них в список охраняемых объектов. Минкульт отреагировал заказом экспертизы, которая подтвердила ценность комплекса. Министр культуры РТ был готов утвердить статус ОКН, когда застройщик инициировал вмешательство «сверху» (И5): «Министру звонили откуда-то оттуда и говорили: "Не делайте памятник"» (ИЗ).

В дальнейшем события разворачивались на арене заседаний Президентской комиссии, созыв которой в 2017 г. инициировала помощница президента РТ Олеся Балтусова- известная казанская градозащитница и сторонница сохранения казарм. Здесь активисты и чиновники, отстаивавшие казармы и настойчиво производившие их ценность, пытались разными способами противостоять административному ресурсу застройщика. В частности, они «натянули зону исторического поселения» Казани на два ключевых здания (ИЗ), добившись от Комиссии поручения внести здания в предмет охраны исторического поселения как ценный градоформирующий объект. Однако «Унистрой» согласился на единственную уступку: не уничтожать здания детсада и военторга полностью, а перенести их на 150 метров вглубь городка.

Сам перенос представляет собой интересный случай работы с ценностью. С одной стороны, признается ценной материальность здания. С другой- незначимым оказывается все, что традиционно составляет его аутентичность: процессы создания здания, накопленная им история изменений, а также связь с локацией. В отсутствие регламентированных процедур переноса исторических зданий в российском законодательстве сотрудники компании-застройщика осуществили разборку бесконтрольно: местные жители сообщали, что кирпичи не были маркированы, так что процедура сохранения ценности нарушилась. Компания же отчиталась, что имела все разрешения для проведения работ и, поскольку никакой ценности здание не представляет (градозащитникам так и не удалось добиться формального статуса), может вообще не воссоздавать его по прежнему проекту.

Конфликт вокруг исторического квартала на Ильинке в Нижнем Новгороде ретроспективно описывается участниками как «война экспертиз» (И9; И10) или экспертный «пинг-понг» (И13). В ходе борьбы за сохранение каждого здания градозащитники стремились закрепить за ним формальный статус ОКН, заказывая государственные историко-культурные экспертизы. Как правило, такие экспертизы подтверждали целесообразность включения исторических зданий в Единый Госреестр памятников. Помимо стратегических задач, связанных с обеспечением безопасности объектов в долговременной перспективе, проведение экспертиз преследовало тактические 
задачи, поскольку после подачи положительного заключения экспертов в Управление госохраны ОКН Нижегородской области здания получали статус вновь выявленных ОКН, а вместе с ним-и временный иммунитет:

Мы его [закон] использовали для того, чтобы затормозить снос, потому что мы понимали, когда бульдозер уже едет, и мы активировали эту деятельность и приносили экспертизу <... И с этого момента объект становился выявленным (И13).

В ответ чиновники и представители застройщика инициировали контр-экспертизы, авторы которых предсказуемо не обнаруживали в оспариваемых зданиях признаков ОКН. Кроме того, управление ОКН нередко отклоняло положительные экспертизы по формальным признакам и рассматривало оставшиеся заключения в беспрецедентно сжатые сроки (до 24 часов). Подобная стремительность позволила властям санкционировать (а застройщику осуществить) снос, пока градозащитники не подготовили новую экспертизу. Иногда отказ во внесении зданий в Реестр публиковался накануне выходных или государственных праздников, чтобы еще больше ограничить градозащитников во времени и снизить социальное напряжение. В свою очередь активисты регулярно, но безуспешно оспаривали правомерность действий управления ОКН в судах.

\section{Заключение}

Мы показали не только то, как историческая ценность формируется, (пере)определяется или отрицается на разных аренах конфликтов, но и то, какую работу она производит: каким образом она упорядочивает арены и действия игроков на них. Во всех кейсах первыми игроками стали градозащитники, а первые арены, взаимодействие на которых они инициировали, ориентировались на рекрутинг новых игроков. Активисты, историки, архитекторы стремились сделать видимой для других историческую ценность зданий, которая и для них зачастую была неочевидной. С помощью просветительских акций, медиакампаний или уличной политики здания постепенно выводили из «серой» зоны невидимого городского ландшафта, превращали из фона в фигуру, у которой есть четко определенное положение в семантическом поле города. Чтобы историческая ценность стала видимой, необходимо провести работу по созданию контекста, в котором здания обретали значение: подстанция стала точкой в блокадном экскурсионном маршруте, Арские казармы обрели связь с русским офицерством и нашли иностранных «побратимов», а квартал на Ильинке превратился в сокровищницу русского зодчества. Подстанция получила название Блокадной, казармы стали памятником «русской военной готики», а ветхие здания на Ильинке переопределены как ценные образцы деревянного модерна и провинциального классицизма. 
Историческая ценность зданий при этом стала угрозой для застройщиков. Но если в Петербурге девелопер ограничился участием в противостоянии экспертиз на уже существующей арене Совета по культурному наследию, то в Казани кампания в дополнение к переговорам в рамках Президентской комиссии создала еще две арены: одну в кулуарах властных кабинетов, другую- во взаимодействии с жителями аварийных домов, которые, в свою очередь, также восприняли историческую ценность как угрозу и инициировали новые арены в форме обращений в администрацию города, района и республики с запросом на обесценивание казарм. Ценность городской истории столкнулась с ценностью комфортной повседневной жизни. Сходным образом развивался конфликт на Ильинке: здесь спорные решения чиновников и членов экспертного научно-методического совета при управлении ОКН легитимировались лояльностью большинства жильцов.

Как видно из анализа, историческая ценность может быть закреплена как формальный статус, в присуждение которого вовлечены эксперты и чиновники, создающие заключения и регламенты. Так, защитники Блокадной подстанции инициировали процедуры, формально подтверждающие ценность здания, причем каждый раз непризнание формальной ценности подталкивало активистов к новым усилиям по ее производству на неформальных публичных аренах: на круглых столах, в медиа, на экскурсиях, митингах и пикетах, на собраниях градозащитников и акциях ветеранов войны. В свою очередь, результаты взаимодействий на этих неформальных аренах влияли на то, как разворачивались взаимодействия на формальных аренах, где оспаривался статус здания.

Обесценивание зданий Арских казарм застройщиком также вызвало противодействие градозащитников. Эксперты привели в действие механизмы, открывающие новые арены взаимодействия: в частности, инициировали создание Президентской комиссии. Но ни один из способов производства формального статуса исторически ценного объекта не сработал, несмотря на то что большинство игроков, включая представителей власти, были уверены в ценности казарм и стремились закрепить ее. Результаты последовательных взаимодействий на этой арене проблематизировали само понятие исторической ценности. Что ею являлось: сами здания военторга и детсада, расположенные в том месте, где их построили, и в той форме, в какой они сохранились? Их фасады? Материалы, из которых созданы здания, перенесенные в другое место?

В отсутствие массовой поддержки горожан и под давлением коалиции власти и бизнеса нижегородские градозащитники проиграли битвы за исторические здания на Ильинке как на формальных, так и на неформальных аренах. Однако они получили мощный опыт причастности к судьбе квартала, связанный не только с интеллектуальным признанием его ценности и аутентичности, но и с формированием эмоциональной привязанности к зданиям через пространственные тактики защиты. Они 
освоили новые инструменты эстетики убеждения, взращивая идентификацию горожан с исторической застройкой через практики взаимодействия с ее материальностью.

Исследование конфликтов с позиций стратегической интеракционной перспективы показывает процессуальность исторической ценности. Одни арены и результаты взаимодействий на них становятся условиями для возникновения других арен. Мы видим, как в ходе конфликтов игроки постепенно нащупывают, в какую сторону необходимо двигаться для более успешного производства ценности (или обесценивания) здания: на каких аренах собирать сторонников, а на каких- сталкиваться с позициями противников. Объект, таким образом, не просто становится ценностью и закрепляет за собой этот статус в результате работы, проведенной теми или иными акторами. Сама по себе ценность-это скорее процедура. Она актуализируется в момент покушения или обесценивания и включает набор способов обращаться с объектом. В исследованных кейсах историческая ценность включала в себя, с одной стороны, создание общей значимости зданий, а с другой- получение формального статуса, закрепляющего способы обращения с ними. Политики аутентичности и эстетика убеждения в равной степени присутствовали в обоих этих воплощениях ценности как процедуры. Так, члены Совета по культурному наследию, научно-методического совета при управлении ОКН или Президентской комиссии одновременно опирались на чужую экспертизу, определявшую, что является «ценным», а что нет, и сами становились экспертами, присваивая статус «ценности». Горожане и градозащитники тоже, с одной стороны, стремились убедить(ся), что объекты действительно представляют ценность, с другой- сами реализовывали свои политики, создавая категории для номинации объектов и выстраивая семантические связи между объектами и контекстами города и памяти.

Ценность как процедура означает, что не существует никакого окончательного статуса, который можно было бы присвоить объекту. Историческая ценность постоянно переопределяет динамику конфликта и переопределяется сама, становясь то бесспорным фактом, то неформальным статусом, то экспертной позицией, то общим мнением, то формальным статусом, то субъективным ощущением.

\section{Выражение признательности}

Исследование выполнено за счет гранта Российского научного фонда (проект № 18-78-10054) «Механизмы согласования интересов в процессах развития городских территорий».

Редакция благодарит программу «Университетское партнерство» за поддержку и возможность опубликовать данную статью. 


\section{Список источников}

Гладарев Б. С. (2011) Историко-культурное наследие Петербурга: рождение общественности из духа города. О. Хархордин (ред.) От общественного к публичному. СПб.: ЕУСПб: 71-304.

Зверев А.А. (2017) Политическое измерение охраны памятников в России: кейс московского движения Архнадзор. Вестник Российского университета дружбы народов. Серия: Политология, 19 (2): 118-129.

Платонов К. А., Юдина Д.И. (2019) Повестка протестных онлайн-сообществ СанктПетербурга во «ВКонтакте». Мониторинг общественного мнения: экономические и соииальные перемены, 5 (153):226-249.

Семенов А. В. (2019) Корни травы: паттерны низовой городской мобилизации в России. Сочиологические исследования, (12):29-37.

Тыканова Е. В. (2019) Уровни участия локальных активистов в борьбе за городское пространство. Л.А. Гайнутдинова, М.В. Невзоров (ред.) Город. Среда. Политика. 2018. СПб: РГПУ им. А. И. Герцена: 37-42.

Bell H. (2011) Listing, 'Significance' and Practised Persuasion at Spa Green Housing Estate, London. Social \& Cultural Geography, 12 (3): 223-242.

Craith M. N. (2007) Cultural Heritages: Process, Power, Commodification. In: U. Kockel, M. N. Craith (eds.) Cultural Heritages as Reflexive Traditions. London: Palgrave Macmillan: 1-18.

Foster S. M., Jones S. (2019) Concrete and Non-Concrete: Exploring the Contemporary Authenticity of Historic Replicas through an Ethnographic Study of the St John's Cross Replica, Iona. International Journal of Heritage Studies, 25 (11): 1169-1188.

Jacobs J. M., Merriman P. (2011) Practising Architectures. Social \& Cultural Geography, 12 (3): 211-222.

Jacobsson K., Korolczuk E. (2020) Mobilizing Grassroots in the City: Lessons for Civil Society Research in Central and Eastern Europe. International Journal of Politics, Culture, and Society, (33): 125-142.

Jasper J. M., Duyvendak J. W. (eds.) (2015) Players and Arenas: The Interactive Dynamics of Protest. Amsterdam: Amsterdam University Press.

Jethro D. H. (2015) Aesthetics of Power: Heritage Formation and the Senses in Post-Apartheid South Africa. Doctoral dissertation. University of Utrecht.

Jones S. (2010) Negotiating Authentic Objects and Authentic Selves. Beyond the Deconstruction of Authenticity. Journal of Material Culture, 15 (2): 181-203.

Jones S., Yarrow T. (2013) Crafting Authenticity: An Ethnography of Conservation Practice. Journal of Material Culture, 18 (1): 3-26.

Mayer M. (2016) Neoliberal Urbanism and Uprisings across Europe. In: M. Mayer, C. Thörn, H. Thörn (eds.) Urban Uprisings: Challenging the Neoliberal City in Europe. London: Palgrave Macmillan:57-92.

Tykanova E., Khokhlova A. (2020) Grassroots Urban Protests in St. Petersburg: (Non-) Participation in Decision-Making about the Futures of City Territories. International Journal of Politics, Culture, and Society, (33): 181-202.

Van de Port M., Meyer B. (2018) Heritage Dynamics: Politics of Authentication, Aesthetics of Persuasion and the Cultural Production of the Real. In: B. Meyer, M. van de Port (eds.) Sense and Essence: Heritage and the Cultural Production of the Real. London: Berghahn: 1-39.

Winner L. (1980) Do Artifacts Have Politics? Daedalus, 1 (109): 121-136. 
Lybov Chernysheva, Anisya Khokhlova

\section{CREATING VALUE AND AUTHENTICITY: URBAN CONFLICTS AROUND HISTORICAL BUILDINGS}

This paper considers the production of historical value of buildings and examines the role of this process in the dynamics of (re)development conflicts. The authors focus on three cases from big Russian cities: recent conflicts around the demolition of Blockade electrical substation in St. Petersburg, Arskie quarters in Kazan and historic buildings in Ilyinskaya Street, Nizhny Novgorod. They argue that historical value and authenticity do not exist in these conflicts as something given: instead, they are claimed, legitimized, contested or revised in the actions and rhetoric of various actors. To grasp the dynamics of historical value/authenticity formation, the authors apply two concepts: politics of authentication and aesthetics of persuasion. Using strategic interaction perspective (the analytical framework accounting for conflict players and arenas), they show what labour historical value performs and how it orders the arenas of conflicts and the (inter)actions of actors in these arenas. In the cases under study, the value of buildings was a procedure that included, on the one hand, detailed work in the generation of contexts, categories and semantic continuums in/through which buildings became meaningful and, on the other hand, struggles for the formal status of 'valuable objects.' This historic value (not) created in various arenas shaped further conflictual interactions, opened up new arenas, engaged new players or excluded old ones. The research shows that an object does not simply become valuable and preserve this status as a result of efforts taken by experts, lobbyists, activists, local residents and other actors. Instead, in the explored cases the value of buildings was a procedure that was launched when the buildings were impinged or dismissed, and that included a set of (un) allowed ways of dealing with objects and strategies designed to reproduce the allowed ones and exclude the unallowed ones.

Keywords: historical heritage, authenticity, urban conflicts, city protecting movements, strategic interaction perspective

DOI: 10.17323/727-0634-2021-19-2-223-238

\section{References}

Bell H. (2011) Listing, 'Significance' and Practised Persuasion at Spa Green Housing Estate, London. Social \& Cultural Geography, 12 (3):223-242.

Lyubov Chernysheva- Research Associate, The Sociological Institute of the RAS - Branch of the Federal Center of Theoretical and Applied Sociology of the Russian Academy of Sciences, St. Petersburg, Russian Federation. Email: 1.a.chernysheva@gmail.com

Anisya Khokhlova- Cand. Sci. (Sociol.), Associate Professor, Chair of Sociology of Culture and Communication, St. Petersburg State University, Russian Federation. Email: a.khokhlova@spbu.ru 
Craith M.N.(2007)Cultural Heritages: Process, Power, Commodification. In: U. Kockel, M.N. Craith (eds.) Cultural Heritages as Reflexive Traditions. London: Palgrave Macmillan: 1-18.

Foster S. M., Jones S. (2019) Concrete and Non-Concrete: Exploring the Contemporary Authenticity of Historic Replicas through an Ethnographic Study of the St John's Cross Replica, Iona. International Journal of Heritage Studies, 25 (11): 1169-1188.

Gladarev B. S. (2011) Istoriko-kul'turnoye naslediye Peterburga: rozhdeniye obshchestvennosti iz dukha goroda [Historical and Cultural Heritage of St. Petersburg: the Birth of the Public from the Spirit of the City]. In: O. Kharkhordin (ed.) Ot obshchestvennogo k publichnomu [From the Common to the public]. St. Petersburg: EUSP Press: 71-304.

Jacobs J. M., Merriman P. (2011) Practising Architectures. Social \& Cultural Geography, 12 (3): 211-222.

Jacobsson K., Korolczuk E. (2020) Mobilizing Grassroots in the City: Lessons for Civil Society Research in Central and Eastern Europe. International Journal of Politics, Culture, and Society, (33): 125-142.

Jasper J. M., Duyvendak J. W. (eds.) (2015) Players and Arenas: The Interactive Dynamics of Protest. Amsterdam: Amsterdam University Press.

Jethro D. H. (2015) Aesthetics of Power: Heritage Formation and the Senses in Post-Apartheid South Africa. Doctoral dissertation. University of Utrecht.

Jones S. (2010) Negotiating Authentic Objects and Authentic Selves. Beyond the Deconstruction of Authenticity. Journal of Material Culture, 15 (2): 181-203.

Jones S., Yarrow T. (2013) Crafting Authenticity: An Ethnography of Conservation Practice. Journal of Material Culture, 18 (1):3-26.

Mayer M. (2016) Neoliberal Urbanism and Uprisings across Europe. In: M. Mayer, C. Thörn, H. Thörn (eds.) Urban Uprisings: Challenging the Neoliberal City in Europe. London: Palgrave Macmillan: 57-92.

Platonov K. A., Yudina D. I. (2019) Povestka protestnykh onlayn-soobshchestv Sankt-Peterburga vo 'VKontakte' [Agenda of Protest Online Communities of St. Petersburg on VKontakte]. Monitoring obshchestvennogo mneniya: ekonomicheskiye i sotsial'nyye peremeny [Opinion Monitoring: Economic and Social Change], 5 (153): 226-249.

Semenov A. V. (2019) Korni travy: patterny nizovoy gorodskoy mobilizatsii v Rossii [The Roots of the Grass: Patterns of Grassroots Urban Mobilization in Russia]. Sotsiologicheskiye issledovaniya [Sociological Studies], (12):29-37.

Tykanova E. V. (2019) Urovni uchastiya lokal'nykh aktivistov v bor'be za gorodskoye prostranstvo [Levels of Participation of Local Activists in the Struggle for Urban Space]. In: L. A. Gaynutdinova, M. V. Nevzorov (eds.) Gorod. Sreda. Politika. 2018 [City. Environment. Policy]. St. Petersburg: RGPU im. A.I. Gertsena: 37-42.

Tykanova E., Khokhlova A. (2020) Grassroots Urban Protests in St. Petersburg: (Non-) Participation in Decision-Making about the Futures of City Territories. International Journal of Politics, Culture, and Society, (33): 181-202.

Van de Port M., Meyer B. (2018) Heritage Dynamics: Politics of Authentication, Aesthetics of Persuasion and the Cultural Production of the Real. In: B. Meyer, M. van de Port (eds.) Sense and Essence: Heritage and the Cultural Production of the Real. London: Berghahn: 1-39.

Winner L. (1980) Do Artifacts Have Politics? Daedalus, 1 (109): 121-136.

Zverev A. A. (2017) Politicheskoye izmereniye okhrany pamyatnikov v Rossii: keys moskovskogo dvizheniya Arkhnadzor [The Political Dimension of Monuments Protection in Russia: the Case of Moscow Movement Arhnadzor]. Vestnik Rossiyskogo universiteta druzhby narodov. Seriya Politologiya [Bulletin of RUDN University. Political science], 19 (2): 118-129. 